\title{
Determinants of tuberculosis patients attending Directly Observed Treatment Short course (DOTS) centre for prevention of default in TB treatment
}

\author{
Manoj Kumar Yadavi, Mohit Raghav", S. S. Chaudhary ${ }^{3}$, Manisha $^{4}$ \\ 1,2,4 Assistant Professor, ${ }^{\mathbf{3}}$ Associate Professor, Dept. of Community Medicine, ${ }^{1,3,4} \mathrm{~S}$ N Medical College, Agra, Uttar Pradesh, ${ }^{\mathbf{2}} \mathrm{G}$ S Medical \\ \& Hospital, Hapur, Uttar Pradesh, India \\ *Corresponding Author: Mohit Raghav \\ Email: mohitrghv6@gmail.com
}

\begin{abstract}
Introduction: It was necessary to understand the reasons for default after initiation of the treatment and plan strategies to reduce default and thereby increase the success of treatment outcome.

Materials and Methods: The present observational cross-sectional study was carried out in selected DOTS centers of district Ghaziabad Department of Community Medicine, Santosh Medical College, Ghaziabad. All new sputum smear positive pulmonary tuberculosis patients were taking treatment from sampled DOTS Centers. The study was carried out in one year from May 2014 to April 2015.

Results: $45.7 \%$ tuberculosis patients were unemployed. $35.29 \%$ of TB patients were educated up to primary $24.70 \%$ pt were illiterate. $54.11 \%$ of TB patients belong to upper lower class. $34.11 \%$ were in lower class. Among the TB patients $76.47 \%$ were smoker whereas $23.53 \%$ were non smoker. Among the TB patients $77.65 \%$ were alcoholic whereas $22.35 \%$ were non alcoholic. $83.53 \%$ TB patients had no family h/o of contact while $16.47 \%$ TB patients had Family h/o of contact. Among tuberculosis patients $77.65 \%$ were aware about the curability of tuberculosis while $22.35 \%$ were not aware about the curability of TB. $34.12 \%$ patients were aware about Modes of Transmission of Tuberculosis and $65.88 \%$ TB patients were not aware about Modes of Transmission of Tuberculosis.

Conclusion: It was concluded that socioeconomic standard of tuberculosis is low and give health education to improve personal habit and stop TB Transmission. Awareness about modes of transmission of tuberculosis was low. Awareness about curability of tuberculosis and knowledge and proper treatment of pulmonary Tuberculosis is poor.
\end{abstract}

Keywords: curability, DOTS Centre, mode of transmission, occupation, socioeconomic status, TB patients.

\section{Introduction}

It was the first infectious disease declared by the WHO as a Global health emergency. ${ }^{1}$ Men are more commonly affected than women. The case notifications were higher in males than in females most countries. There were 1.4 million smear-positive TB cases in men and 775,000 in women in $2004 .^{2}$ The association between poverty and TB is well recognized, and the highest rates of TB were found in the poorest section of the community. ${ }^{3} \mathrm{~TB}$ occurs more frequently among low-income people living in overcrowded areas and persons with little schooling. ${ }^{4}$ Poverty may result in poor nutrition which may be associated with alterations in immune function. On the other hand, poverty resulting in overcrowded living conditions, poor ventilation, and poor hygiene-habits is likely to increase the risk of transmission of TB. ${ }^{5}$

Fundamentally TB control is based on preventing the transmission of the infectious agent causing TB. This can be achieved by identifying people with infectious TB and curing them of their disease so that they cannot transmit the disease further.

$\mathrm{TB}$ is a communicable disease requiring prolonged treatment. The World Health Organization (WHO) declared TB a global public health emergency in 1993 and since then intensified its efforts to control the disease worldwide. ${ }^{6}$ Tuberculosis affects one third of the world's population and India alone accounts for one-fifth of the world's new TB cases. $^{7}$

Global Tuberculosis report (2015) released by the WHO has revealed that there were an estimated 9.6 million new TB cases 5.4 million among men, 3.2 million among women and 1.0 million among children in the year $2014 .{ }^{8}$ Since the advent of HIV, the incidence of TB had steadily increased and it is responsible for $26 \%$ of all avoidable adult deaths in the developing world. ${ }^{9}$ There were also 1.5 million TB deaths (1.1 million among HIV-negative people and 0.4 million among HIV-positive people) in 2014. With a timely diagnosis and correct treatment almost all people with TB can be cured. TB is slowly declining each year and it estimated that 43 million lives were saved between 2000 and 2014 through effective diagnosis and treatment. ${ }^{8}$ Hence this study therefore attempts to study the determinants of Tuberculosis patients attending Directly Observed Treatment Short course (DOTS) centre for prevention of default in TB treatment.

\section{Materials and Methods}

The present observational cross-sectional study was carried out in selected DOTS centers of district Ghaziabad Department of Community Medicine, Santosh Medical College, Ghaziabad. All new sputum smear positive pulmonary tuberculosis patients were taking treatment from sampled DOTS Centers. The study was carried out in one year from May 2014 to April 2015.

\section{Sample size}

According to Government of India (2007) by using overall prevalence of defaulter $10.2 \%$ among patients put on DOTS (82).

The sample size was calculated by the formula ( $\mathrm{n}=$ Z.Z.P.Q/L.L). 
Sample Size $(\mathrm{n})=1.96 \times 1.96 \times 10.2 \times 89.8 / 2.04 \times 2.04=845.52$ $=846$

$\mathrm{n}$ is the desired sample size

$\mathrm{P}$ is prevalence of Defaulters among DOTS patient $=10.2 \%$ $\mathrm{Q}=(100-\mathrm{p})$

$\mathrm{L}=20 \%$

Substituting all the values we get sample size $(n)=846$

Round figure is 850 .

\section{Inclusion criteria}

All new sputum smear positive pulmonary tuberculosis patient attended treatment in sampled dots centers whose age was >15 years from October 2014 till my desired sample size 850 patient were seen on working days.

\section{Exclusion criteria}

1. Patient, whose contact information was incomplete.

2. Patient, who died or transferred to other DOTS centre.

\section{Sampling technique}

Multistage sampling was used to cover the sample size for present study.

\section{Stage-1 Selection of tuberculosis unit (TU)}

The list of tuberculosis unit along with their designated microscopic centers and DOTS centers was obtained from district tuberculosis center. There were two TU in Ghaziabad city named as 1 . District tuberculosis clinic Ghaziabad 2. ESI hospital Sahibabad selected for study.

\section{Stage -II Selection of designated microscopic centers (DMCs)}

In second stage three designated microscopic centers (DMCs) from each TU were selected randomanly. District tuberculosis clinic Ghaziabad (TU) had five DMCs out of these three DMCs 2,3and 5 were selected randomly,

ESI Hospital Sahibabad had five DMCs named as out of five DMCs 1, 4 and 5 were selected randomly.

\section{Stage III Selection of DOTs centers}

All the DOTS centers under these selected DMCs were taken for study. All the new sputum smear positive (NSP) patients put on treatment on selected DOTS centers during the study period were taken for study till the desired sample size was achieved.

The selected DOTS were visited and the TB patients were carefully briefed about the purpose of the study with a written consent so as to get full co-operation in conducting the study. These were $850 \mathrm{~TB}$ patients from all selected DOTS questioned with self-administered well-designed pretested and close-ended questionnaire with prior permission from the patients.

\section{Data processing and analysis}

Data was coded and transferred to a master chart and simple and correlated tables were prepared and analyzed using SPSS.

\section{Results}

$41.17 \%$ of TB patients were from 15-25yrs age group, $30.58 \%$ from $26-35 \mathrm{yrs}, 23.52 \%$ from $36-45 \mathrm{yrs}$ and $4.70 \%$ from $>45$ yrs age group. Table 1 Majority $54.1 \%$ of $\mathrm{Tb}$ patients were females and $45.9 \%$ males. $75.29 \%$ TB patients were Hindus, 22.35\% Muslims and 2.35\% Sikh/Christian.

Almost half $(49.41 \%)$ of TB Patients were from other backward category (OBC), 35.29\% from scheduled caste (SC), and $15.29 \%$ from general category. $44.71 \%$ were from nuclear family, $31.76 \%$ from joint family and $23.53 \%$ from three generation family.

Table 1 indicates that $45.7 \%$ tuberculosis patients were unemployed, $20 \%$ from skilled worker, $14.1 \%$ unskilled worker, 9.4\% semiskilled, $5.9 \%$ semi professional, $4.7 \%$ professional and $1.2 \%$ were having their own shop.

Table 1: Occupation wise distribution of tuberculosis patients

\begin{tabular}{|l|c|c|}
\hline Occupation & Number (n) & $\begin{array}{c}\text { Percentage } \\
(\%)\end{array}$ \\
\hline Un employed & 380 & 45.70 \\
\hline Un skilled worker & 120 & 14.10 \\
\hline Semiskilled worker & 80 & 9.40 \\
\hline Skilled worker & 170 & 20.0 \\
\hline Clerical/shop owner & 10 & 1.20 \\
\hline $\begin{array}{l}\text { Semi professional } \\
\text { worker }\end{array}$ & 50 & 5.90 \\
\hline Professional worker & 20 & 4.70 \\
\hline Total & 850 & 100 \\
\hline
\end{tabular}

Majority $54.11 \%$ of $\mathrm{Tb}$ patients were from upper lower class. $34.11 \%$ from lower class followed by $10.58 \%$ from lower middle class, and $1.17 \%$ from upper middle class (Table 2).

Table 2: Socio-economic status wise distribution of tuberculosis patients as per Kuppuswamy's scale

\begin{tabular}{|l|c|c|}
\hline Socio-economic status & Number & $\begin{array}{c}\text { Percentage } \\
(\mathbf{\%})\end{array}$ \\
\hline Lower class & 290 & 34.11 \\
\hline Upper lower class & 460 & 54.11 \\
\hline Lower middle class & 90 & 10.58 \\
\hline Upper middle class & 10 & 1.17 \\
\hline Total & 850 & 100 \\
\hline
\end{tabular}

Regarding h/o of contact $83.53 \%$ TB patients had no Family $\mathrm{h} / \mathrm{o}$ of contact and $16.47 \% \mathrm{~Tb}$ patients had the history of contact with TB case in home/work place (Table 3 ).

Table 3: Distribution of study subject according to the history of contact with TB case in home/work place

\begin{tabular}{|l|c|c|}
\hline $\begin{array}{l}\text { Family h/o of } \\
\text { contact }\end{array}$ & $\begin{array}{l}\text { Number } \\
(\mathbf{n = 8 5 0})\end{array}$ & Percentage (\%) \\
\hline Yes & 140 & 16.47 \\
\hline No & 710 & 83.53 \\
\hline Total & 850 & 100 \\
\hline
\end{tabular}


Table 4 indicates that $77.65 \%$ were know about the curability of tuberculosis 22.35 were not know about the curability of TB.

Table 4: Distribution of study subjects according to knowledge of curability of tuberculosis

\begin{tabular}{|l|c|c|}
\hline \multicolumn{1}{|c|}{ Awareness } & Numbers & Percentage (\%) \\
\hline Curable & 660 & 77.65 \\
\hline Not curable & 190 & 22.35 \\
\hline Total & 850 & 100 \\
\hline
\end{tabular}

Table 5 indicates that $34.12 \%$ patient knew and $65.88 \%$ TB patient didn't not know about the modes of transmission of TB.

Table 5: Distribution of study subjects according to the knowledge about modes of transmission of tuberculosis

\begin{tabular}{|l|c|c|}
\hline Awareness & Numbers & Percentage (\%) \\
\hline Yes & 290 & 34.12 \\
\hline No & 560 & 65.88 \\
\hline Total & 850 & 100 \\
\hline
\end{tabular}

Table 6 depicts that $77.65 \%$ TB patient were know about hazards of irregular treatment and $22.35 \%$ were not know.

Table 6: Distribution of study subjects according to knowledge of hazards of irregular treatment

\begin{tabular}{|l|c|c|}
\hline Awareness & Numbers & Percentage (\%) \\
\hline Aware & 660 & 77.65 \\
\hline Not aware & 190 & 22.35 \\
\hline Total & 850 & 100 \\
\hline
\end{tabular}

It was observed that $62.35 \%$ of TB patients aware about the duration of treatment and $37.65 \%$ not aware of duration of treatment.

Table 7: Distribution of study subjects according to knowledge about correct duration of treatment

\begin{tabular}{|l|c|c|}
\hline Awareness & Numbers & Percentage (\%) \\
\hline Aware & 530 & 62.35 \\
\hline Not aware & 320 & 37.65 \\
\hline Total & 850 & 100 \\
\hline
\end{tabular}

\section{Discussion}

In my study $45.7 \%$ tuberculosis patients were unemployed, $20 \%$ skilled worker, $14.1 \%$ unskilled worker, $9.4 \%$ semiskilled, $5.9 \%$ semi professional, $4.7 \%$ professional and $1.2 \%$ their own shop. A similar study by P.G. Gopi et al ${ }^{10}$ 2007 in south-India showed in their study that $35 \%$ were unemployed.

In my study $54.11 \%$ of TB patients were from upper lower class, $34.11 \%$ from lower class, $10.58 \%$ from lower middle class, and $1.17 \%$ from in upper middle class. In a similar study done by S.K. Juvekar et $\mathrm{al}^{11} 1995$ in showed that $59 \%$ of TB pt were from lower socioeconomic class. A similar study by Kar M and Logaraj M $^{12} 2010$ conducted in
Tamil Nadu showed that More than $70 \%$ of the people belonged to lower income group.

In this study shows that $77.65 \%$ knew about the curability of tuberculosis while 22.35 did not know about the curability of TB. In a similar study done by S.K. Juvekar et $\mathrm{al}^{11} 1995$ showed that majority $(88 \%)$ believed that tuberculosis is completely curable. Only $7 \%$ denied curability, probably due to their experience of persistent symptoms, not getting any relief from drugs, suffering from side-effects of drugs, etc. Madhu Vidhani, Parul Vadgama ${ }^{12}$ 2010 conducted a study in Surat, Gujarat showed that $95.5 \%$ patients thought that tuberculosis is curable. Salman Khalil et al $^{14} 2011$ conducted a study in Aligarh showed that Majority of the patient $95.5 \%$ believed that tuberculosis is curable.

In my study shows that regarding knowledge about modes of transmission, $34.12 \%$ patients knew about mode of transmission and $65.88 \%$ TB patients did not know. Kar M and Logaraj $\mathbf{M}^{12} 2010$ conducted a study in Tamil Nadu showed that only $20 \%$ patients were aware about the mode of spread and the rest $80 \%$ didn't have any knowledge or wrong knowledge about the mode of spread of TB. Madhu Vidhani, Parul Vadgama ${ }^{13} 2010$ conducted a study in Surat, Gujarat showed that $(46.6 \%)$ patients were aware that tuberculosis infection could be transmitted from one individual to another through close contact and coughing. Salman Khalil et al ${ }^{14} 2011$ conducted a study in Aligarh showed that $96.6 \%$ of patient were aware that tuberculosis could be transmitted from one person to another. Ekwaro A Obuku et $\mathrm{al}^{15} 2012$ conducted a study in Uganda showed that $(54.3 \%)$ were aware about the mode transmission.

In this study shows that awareness about hazards of irregular treatment was high, $77.65 \mathrm{~TB}$ patients knew and $22.35 \%$ did not know. In a similar study done by S.K. Juvekar et $\mathrm{al}^{11} 1995$ Showed that majority of the patients $(83 \%)$ were of opinion that health deteriorates or disease worsens due to irregular/intermittent treatment. Madhu Vidhani, Parul Vadgama ${ }^{13} 2010$ conducted a study in Surat, Gujarat showed that almost all the patients were aware that if anti tubercular drug is not taken than it could adversely affect their health.

In this study shows that $62.35 \%$ of TB patients were knew and $37.65 \%$ did not know about the correct duration of treatment. Similar study done by Madhu Vidhani, Parul Vadgama $^{13} 2010$ conducted a study in Surat, Gujarat showed that Awareness about the duration (6-9 months) was correctly known to only $(32.9 \%)$ patients.

\section{Conclusion}

It was concluded maximum tuberculosis patients were unemployed. One fourth of TB patients were illiterate. $54.11 \%$ of TB patients belong to upper lower class. Among the TB patients $76.47 \%$ were smoker whereas $23.53 \%$ were non smoker. Among the TB patients $77.65 \%$ were alcoholic whereas $22.35 \%$ were non alcoholic. Regarding Family h/o of contact, it was seen that $83.53 \%$ TB patients had no family h/o of contact while $16.47 \%$ TB patients had Family h/o of contact. Among tuberculosis patients $77.65 \%$ were 
aware about the curability of tuberculosis while $22.35 \%$ were not aware about the curability of TB. Regarding awareness about modes of transmission, it was observed that $34.12 \%$ patients were aware about Modes of Transmission of Tuberculosis and $65.88 \%$ TB patients were not aware about Modes of Transmission of Tuberculosis.

\section{Acknowledgment}

I would like to express my profound gratitude to all the participants.

\section{Source of Funding}

None.

\section{Conflict of Interest}

None.

\section{Ethical Approval}

Permission for the study was obtained from the College authorities prior to commencement.

\section{References}

1. Kochi A. The global tuberculosis situation and the new control strategy of the World Health Organization. Tubercle 1991;71:1-6.

2. Dye C. Global epidemiology of tuberculosis. Lancet. 2006;367:938-40.

3. Davies PD. Tuberculosis: the global epidemic. J IndMed Assoc. 2000; 98:100-02.

4. Cantwell MF, Mckenna MT, McCray E, Onorato IM. Tuberculosis and race/ethnicity in United States: impact of socioeconomic status. Am J Respir Crit Care Med. 1998;157:1016-20.

5. Spence DP, Hotchkiss J, Williams CSD, Davies PD. Tuberculosis and poverty. BMJ. 1993;307:759-61.

6. World Health Organization. TB - A Global Emergence. Geneva: World Health Organization; 1994. WHO/TB/94.177.
7. TB India 2009: RNTCP Status Report. Central TB Division, DGHS, Govt. of India.

8. Global Tuberculosis Control Report 2015. Geneva: WHO; 2015.

9. Tuberculosis: The worsening epidemic. WHO. SEARO, (2009).

10. Gopi PG, Vasantha M, Muniyandi M, Chandrasekaran V, Balasubramanian R, Narayanan PR. Risk factors for nonadherence to directly observed treatment (dot) in a rural tuberculosis unit, south India. Indian J Tuberc. 2007;54:66-70.

11. Juvekar SK, Morankar SN, Dalai DB, Rangan SG, Khanvilkar SS, Vadair AS, et al. Deshpande social and operational determinants of patient behaviour in lung tuberculosis Indian $J$ Tub. 1995;42:87.

12. Kar M, Logaraj M. Awareness, attitude and treatment seeking behavior regarding Tuberculosis in a rural area of Tamil Nadu. Indian J Tuberc. 2010;57: 226-9.

13. Vidhani M, Vadgama P. Awareness regarding pulmonary tuberculosis - a study among patient taking treatment of tuberculosis in rural Surat, Gujarat. Natl J Med Res. 2012;2(4):452-4.

14. Khalil S, Ahmad E, Khan Z, Perwin N. A study of knowledge and awareness regarding pulmonary tuberculosis in patients under treatment for tuberculosis in a rural area of Aligarh UP. Indian J Community Health. 2011;23(2):45-89.

15. Obuku EA, Meynell C, Kiboss-Kyeyune J, Blankley S, Atuhairwe C, Nabankema E, et al. Socio-demographic determinants and prevalence of Tuberculosis knowledge in three slum populations of Uganda. BMC Public Health. 2012;12:536

How to cite this article: Yadav MK, Raghav M, Chaudhary SS, Manisha. Determinants of tuberculosis patients attending Directly Observed Treatment Short course (DOTS) centre for prevention of default in TB treatment. Indian $J$ Forensic Community Med. 2020;7(1):47-50. 